\title{
Nitrogen enrichment of AISI 409 stainless steel by solution heat treatment after plasma nitriding
}

\author{
E. M. Berton, J. C. K. das Neves, M. Mafra, P. C. Borges* \\ Federal University of Technology - Paraná, Group for Research on Materials Tribology and Surfaces, Mechanical \\ Engineering Department, UTFPR, 80230-901 Curitiba, PR, Brazil
}

Received 23 November 2016, received in revised form 13 March 2017, accepted 15 March 2017

\begin{abstract}
This work presents a new treatment for ferritic stainless steels. The Solution Heat Treatment after Plasma Nitriding (SHTPN) of AISI 409 samples resulted in a nitrogen-rich martensitic layer, thicker than $600 \mu \mathrm{m}$, and with $500 \mathrm{HV}(4.90 \mathrm{GPa})$ until $200 \mu \mathrm{m}$. Polarization curves prove that surface hardening has not compromised corrosion resistance.
\end{abstract}

Ke y words: AISI 409 stainless steel, nitrogen enrichment, surface engineering, Solution Heat Treatment after Plasma Nitriding (SHTPN)

\section{Introduction}

Plasma treatments have been widely applied to enhance surface properties of stainless steels [1-4]. While hardness is improved by these treatments, often corrosion resistance is reduced. The compromising of corrosion resistance caused by precipitation of chromium compounds has been overcome by low-temperature plasma treatments [4-6]. However, low-temperature treatments implicate in long processing times and small layers. Another possibility to the hardening of these steels is the High-Temperature Gas Nitriding (HTGN), in which nitrogen diffuses into austenite [78]. Solid solution nitrogen-enriched surfaces can also be achieved by Solution Heat Treatment after Plasma Nitriding (SHTPN). This process consists of the regular surface by nitriding, followed by a diffusion treatment at a material-specific temperature [9-11].

The solution step added by Borges et al. [10], and Reis et al. [11] after the plasma nitriding treatment was successfully applied to austenitic, martensitic and precipitation hardening steels. The hardened layers obtained by introduction of nitrogen in solid solution were successful on retaining the steel corrosion resistance, similarly to what occurs in HTGN, but with a shorter exposition to high temperature. Compared to low-temperature plasma processing, SHTPN produces, in shorter times, considerably thicker layers.
Despite a large number of works devoted to stainless steels [4], it can be found that surface treatments are not often applied to the ferritic grade. In the present work, AISI 409 samples were treated by the SHTPN process, aiming to form a hardened layer without compromising corrosion resistance.

\section{Materials and methods}

Samples of AISI 409 stainless steel with $30 \times 30 \times 5$ $\mathrm{mm}^{3}$ were used in untreated, nitrided and SHTPN conditions. The chemical composition of the steel, measured by atomic absorption spectrometry, is presented in Table 1, and the experimental procedure is summarized in Fig. 1. The samples were plasma nitrided at $783 \mathrm{~K}$ for $7200 \mathrm{~s}$, in a gas mixture of $80 \%$ $\mathrm{N}_{2}+20 \% \mathrm{H}_{2}$ at $400 \mathrm{~Pa}$. A pulsed DC power supply was used to impose a $-600 \mathrm{~V}$ potential, with samples acting as the cathode of the discharge.

The solution annealing was carried out at $1373 \mathrm{~K}$ for $3600 \mathrm{~s}$, in an argon atmosphere $(99.99 \%$ pure), to prevent the high-temperature oxidation. The samples were oil quenched directly from the solution temperature. This quench was intended to suppress the precipitation of nitrides and formation of sigma phase $[12]$.

After treatments, the samples were ground to re-

\footnotetext{
*Corresponding author: tel.: + 55 (41) 33104499; e-mail address: pborges@utfpr.edu.br
} 
Table. 1. Chemical composition of AISI 409 samples (wt.\%)

\begin{tabular}{ccccccccccc}
\hline Elements & $\mathrm{C}$ & $\mathrm{Cr}$ & $\mathrm{Ni}$ & $\mathrm{Si}$ & $\mathrm{Mn}$ & $\mathrm{Mo}$ & $\mathrm{Cu}$ & $\mathrm{Co}$ & $\mathrm{P}$ & $\mathrm{Ti}$ \\
\hline & 0.006 & 10.8 & 0.32 & 0.418 & 0.20 & 0.053 & 0.023 & 0.041 & 0.033 & 0.215 \\
\hline
\end{tabular}

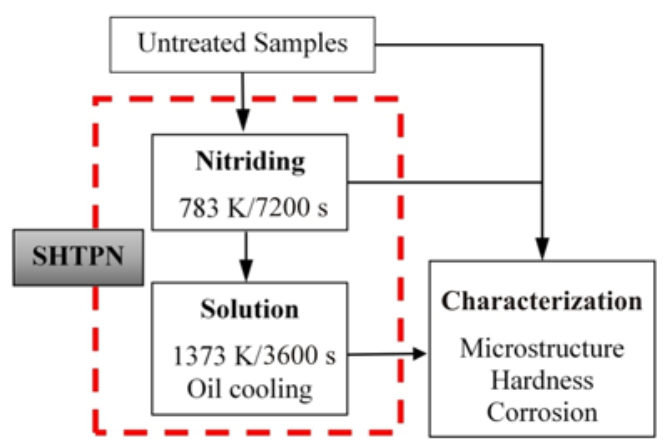

Fig. 1. Flowchart of the experimental procedure.

move about $200 \mu \mathrm{m}$ of a superficial porous layer, and then cross-sectioned for metallographic analysis. Microstructural characterization was performed using an Olympus BX51M optical microscope and a Carl Zeiss EVO MA15 scanning electron microscope. Hardness profile measurements $(0.49 \mathrm{~N})$ were carried out in a Shimadzu HMV-2 tester. The nitrogen content of the treated samples was measured by WDS using an Oxford WDS spectrometer coupled to a Carl Zeiss S440 scanning electron microscope. XRD patterns were obtained in a Shimadzu XRD-7000 diffractometer. The corrosion resistance was evaluated by potentiodynamic cyclic curves in $\mathrm{NaCl} 0.5 \mathrm{~mol} \mathrm{~L}^{-1}$ $\left(500 \mathrm{~mol} \mathrm{~m}^{-3}\right)$ solution. Tests were performed in an Iviun-n-Stat multichannel potentiostat manufactured by Iviun Technologies, with an electrochemical cell built accordingly to ASTM G150.

\section{Results and discussion}

The microstructures of the samples are presented in Fig. 2. The bulk structure of untreated sample (Fig. 2a) remains unchanged after nitriding, and the only modification detected in the nitrided sample (Fig. 2b) is a $50 \mu \mathrm{m}$ thick composite layer. In Fig. 2c it can be observed that a layer of nitrogen martensite thicker than $600 \mu \mathrm{m}$ was produced by SHTPN. Below this layer, there is a transition region with small martensitic areas at grain boundaries. It must be noticed that the presence of precipitates was not detected even at high magnifications on SHTPN surfaces. It can also be noticed from Fig. 2c that SHTPN promoted grain growth. A new sequence of treatments, including a second quenching and tempering cycle, is currently under investigation, as an attempt to refine
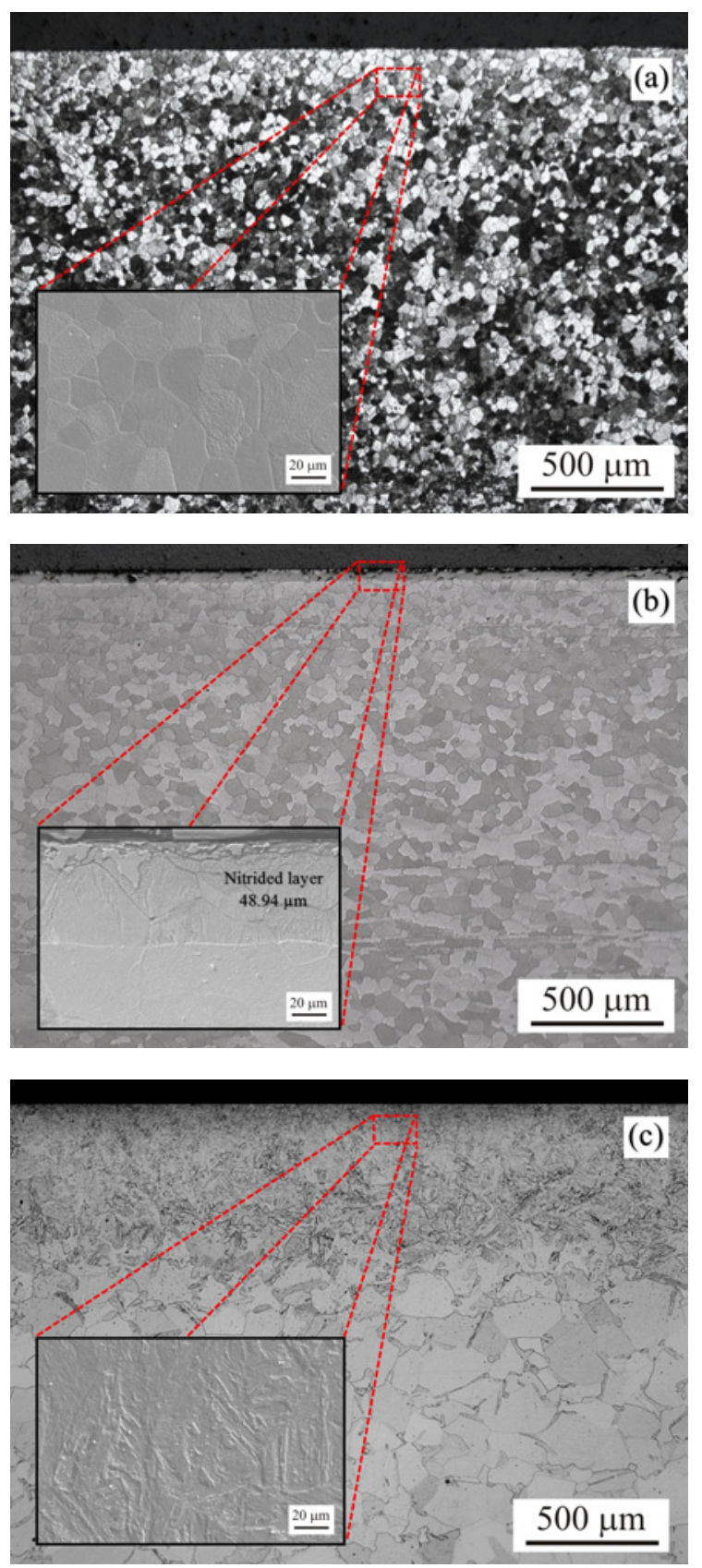

Fig. 2. SEM micrographs of AISI 409 stainless steel for samples: (a) untreated, (b) after plasma nitriding, (c) after SHTPN (Vilella etchant).

the microstructure and promote stress relief.

The main result of these transformations is the high increase of hardness, as presented in the hardness profiles of Fig. 3. As expected, nitrided sam- 


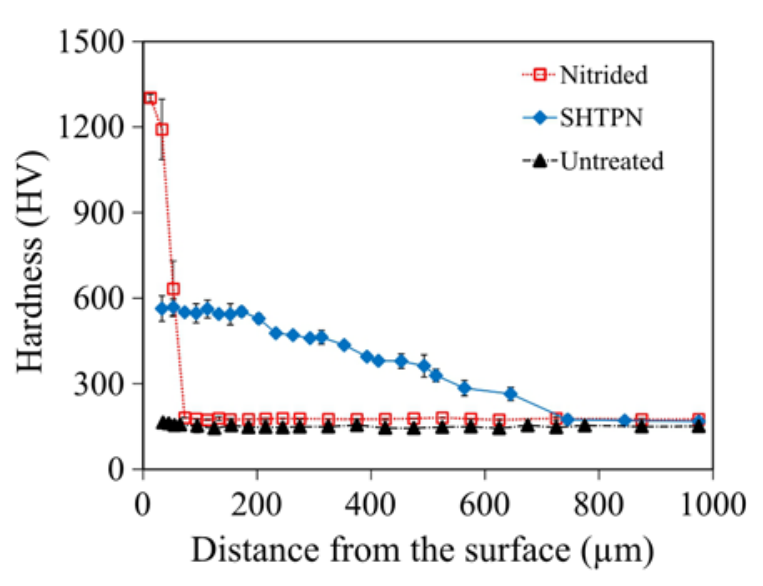

Fig. 3. Hardness profile Vickers sample plasma nitriding compared with SHTPN process and untreated.

ples reached the highest hardness (1300 $\mathrm{HV}_{0.05} /$ $12.75 \mathrm{GPa})$. However, it was restricted to the composite layer $(50 \mu \mathrm{m})$. Similar hardened layers (1200 $\left.\mathrm{HV}_{0.05} / 11.77 \mathrm{GPa}, 30 \mu \mathrm{m}\right)$ were obtained by Cajner et al. [13] in an X17CrNi16-2 (martensitic) steel but with an unwanted core softening, caused by tempering effect. Contrasting with as-nitrided samples, SHTPN led to a surface hardness of $580 \mathrm{HV}(5.69 \mathrm{GPa})$, which is almost constant along the first $200 \mu \mathrm{m}$. After that, a smooth hardness reduction is observed, and at $500 \mu \mathrm{m}$ it is still about $360 \mathrm{HV}(3.53 \mathrm{GPa})$. Only close to $800 \mu \mathrm{m}$ hardness reached $170 \mathrm{HV}(1.67 \mathrm{GPa})$, which corresponds to the hardness of the untreated samples.

This is a very promising result because it is known that, under many wear conditions, surfaces with low hardness gradient have better behavior than hard films or coatings over soft cores. Moreover, this profile suggests that surface properties are extended over $200 \mu \mathrm{m}$ into the material core, which can be very helpful in mechanical design.

The measured nitrogen content and the calculated Pitting Resistance Equivalent Number (PREN) [14] profiles of SHTPN sample are presented in Fig. 4. The results agree with the hardness profile, and show an important enrichment in nitrogen, reaching $0.42 \mathrm{wt} . \%$ at $30 \mu \mathrm{m}$. Besides the hardening effect, nitrogen in solid solution can improve the corrosion resistance of stainless steels $[10,15,16]$, which can be an additional benefit of the SHTPN process.

SHPTN beneficial effects become even more remarkable when the XRD patterns are observed in Fig. 5. While Fe-Cr-N compounds are clearly found in nitrided samples, the SHTPN process was able to dissolve those phases. Comparing untreated to SHTPN samples the only change observed in the XRD pattern are the enlargement and displacement of iron peaks (shown in detail in Fig. 5), which is due to martensitic transformation.

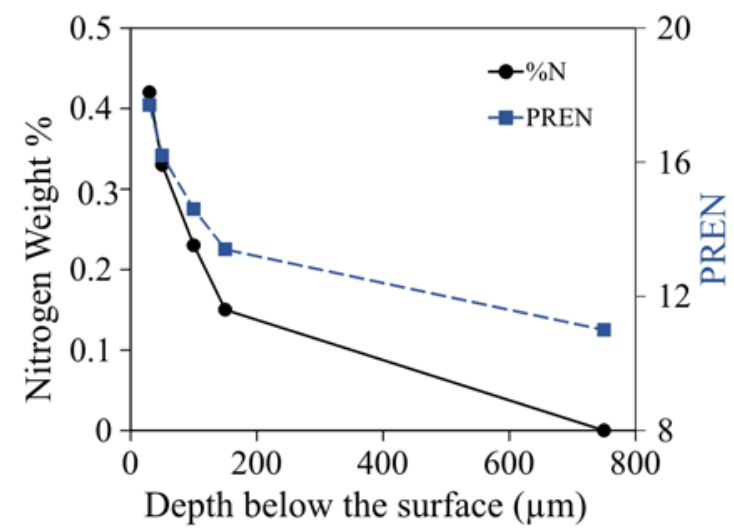

Fig. 4. The relationship between the PREN, the depth and nitrogen content for the obtained AISI 409 steel after SHTPN.

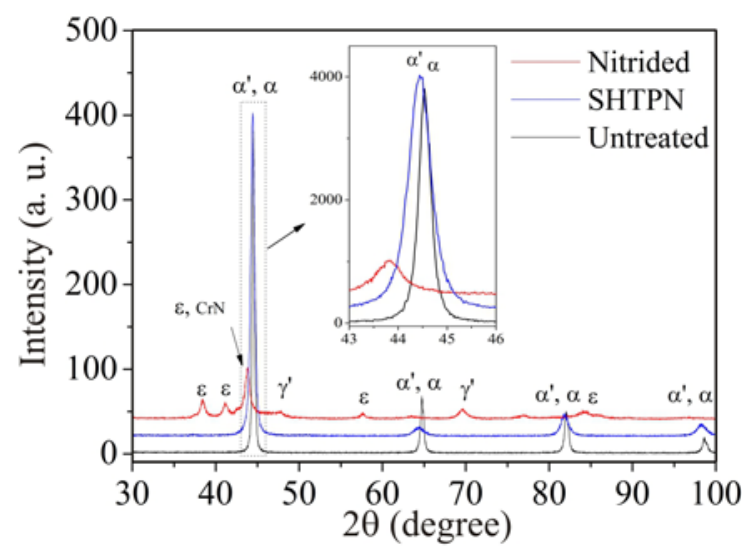

Fig. 5. X-ray diffraction pattern of untreated, plasma nitrided and SHTPN samples of AISI 409.

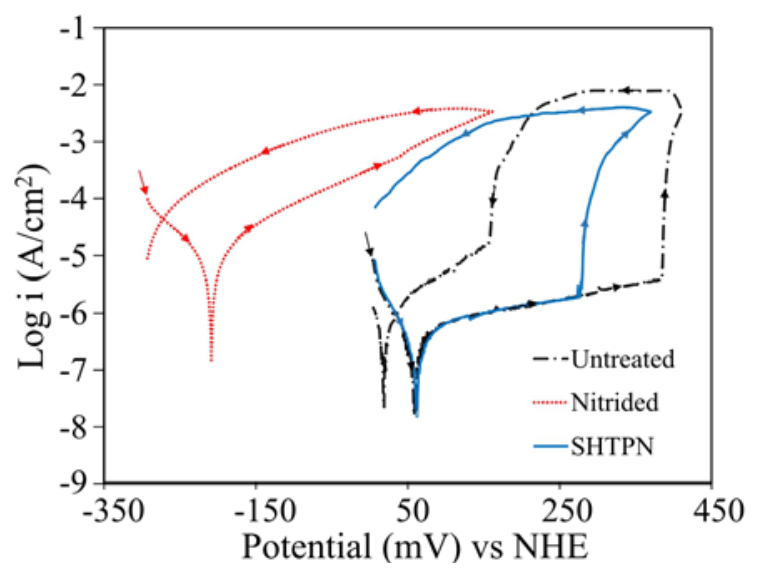

Fig. 6. Cyclic potentiodynamic curves of AISI 409 for untreated, nitrided and SHTPN samples ( $\mathrm{NaCl} 500$ $\left.\mathrm{mol} \mathrm{m} \mathrm{m}^{-3}\right)$.

The cyclic potentiodynamic curves of studied samples are shown in Fig. 6. As can be seen, the precipita- 
Ta b le 2. Hardness and corrosion resistance data of AISI 409 stainless steel compared to literature values

\begin{tabular}{|c|c|c|c|c|c|c|c|}
\hline \multirow{2}{*}{ Ref. } & \multirow{2}{*}{ Steel/Treatment } & \multirow{2}{*}{$\begin{array}{l}\text { Hardness } \\
(\mathrm{HV} / \mathrm{GPa})\end{array}$} & \multirow{2}{*}{$\begin{array}{l}\text { Hardened } \\
\text { layer } \\
(\mu \mathrm{m})\end{array}$} & \multicolumn{4}{|c|}{ Characteristics of cyclic polarization tests } \\
\hline & & & & $\begin{array}{c}E_{\text {corr }} \mathrm{NHE} \\
(\mathrm{mV})\end{array}$ & $\begin{array}{l}E_{\mathrm{pit}} \mathrm{NHE} \\
\quad(\mathrm{mV})\end{array}$ & $\begin{array}{l}\text { Passive } \\
\text { zone }\end{array}$ & Resulting corrosion \\
\hline- & 409/Untreated & $170 \mathrm{HV}_{0.05} / 1.67$ & - & 58 & 384 & Small & Pitting \\
\hline- & 409/SHTPN & $580 \mathrm{HV}_{0.05} / 5.69$ & 650 & 62 & 279 & Small & Pitting \\
\hline$[2]$ & $410 / \mathrm{QT}$ & $262 \mathrm{HV}_{1.0} / 2.57$ & - & -553 & $<-491$ & No & Pitting and crevice \\
\hline$[12]$ & $\mathrm{X} 17 \mathrm{CrNi16}-2 / \mathrm{N}$ & $1386 \mathrm{HV}_{0.05} / 13.59$ & 30 & -854 & - & No & Pitting and crevice \\
\hline$[15]$ & $410 / \mathrm{QT}$ & $\sim 500 \mathrm{HV} / 4.90$ & - & -276 & 31 & Small & Pitting \\
\hline$[15]$ & 410/HTGN & $725 \mathrm{HV}_{0.1} / 7.11$ & 1500 & -289 & 533 & Small & Pitting \\
\hline$[16]$ & Modified 420/QT & $\sim 560 \mathrm{HV} / 5.49$ & - & -456 & $\sim 386$ & Small & Pitting \\
\hline
\end{tabular}

tion of chromium nitrides in the nitrided sample, confirmed by the XRD patterns, resulted in a less noble corrosion potential and an increase of current density, which consequently led to a higher corrosion rate. Cajner et al. [13] observed the same corrosion behavior in plasma nitrided martensitic steel and attributed it to chromium nitride precipitation.

Despite changing from ferrite to nitrogen martensite, the corrosion behavior shows small changes if compared with untreated steel, except for a reduction of pitting corrosion potential. A possible way to improve it is to refine the structure and reduce the residual stress, which is currently under investigation.

In Table 2, hardness and corrosion resistance data of martensitic stainless steels taken from the literature are compared to results from the present work. Analyzing AISI 409 treated by SHTPN and AISI 410 [2, $16]$, it is found that the first presents a better corrosion resistance. Potentiodynamic curves of quenched and tempered (QT) AISI 410 presented lower corrosion and pitting potentials than the values found for SHTPN and also higher current densities, with small or no passive region. The results of Lu et al. [17] studying a modified AISI 420 also found a less noble pit potential than the observed in the present work. These results can be explained by the difference between the types of martensite produced in those steels, carbon martensite on AISI 410 e 420, and nitrogen martensite obtained by SHTPN on AISI 409.

Lopez et al. [16] also studied the corrosion resistance of AISI 410 after high-temperature gas nitriding (HTGN). The pitting potential was increased to $533 \mathrm{mV}$, indicating the beneficial role of nitrogen in solid solution to corrosion resistance. However, this excellent result, which includes a layer $1500 \mu \mathrm{m}$ thick with hardness ranging from $725 \mathrm{HV}$ (7.11 GPa) to $550 \mathrm{HV}$ (5.39), was only achieved after a 21600 s treatment at $1473 \mathrm{~K}$.

In contrast with these results, SHTPN allowed, in a shorter treatment, to increase the hardness of an AISI 409 stainless steel to a level comparable to a $0.4 \% \mathrm{C}$ martensitic steel, and to keep its character- istic corrosion potential, which is intrinsically superior to martensitic steels. Also, further developments of the process can lead to microstructure refining and martensite stress relief, achieving even better results.

\section{Conclusions}

After the treatment of AISI 409 steel by a new hardening process named SHTPN, it is possible to conclude that:

- Martensitic transformation can be achieved in a ferritic stainless steel after its enrichment with nitrogen, by plasma nitriding, and then dissolving it, through a solution treatment, into the iron lattice.

- Nitrogen martensite layers thicker than $600 \mu \mathrm{m}$ can be produced by SHTPN in AISI 409 stainless steel, without precipitation of chromium nitrides.

- A strong hardening can be achieved in the AISI 409 steel without compromising its corrosion potential.

\section{Acknowledgements}

The authors acknowledge CNPq, CAPES, and FA for financial support, and the Oxford Instruments and Multiuser Center for Materials Characterization of UTFPR for performing most of the analysis presented in this work.

\section{References}

[1] Asgari, M., Barnoush, A., Johnsen, R., Hoel, R.: Mater. Sci. Eng. A, 529, 2011, p. 425. doi:10.1016/j.msea.2011.09.055

[2] Li, C. X., Bell, T.: Corr. Sci., 48, 2006, p. 2036. doi:10.1016/j.corsci.2005.08.011

[3] Stinville, J. C., Cormier, J., Templier, C., Villechaise, P.: Mater. Sci. Eng. A, 605, 2014, p. 51. doi:10.1016/j.msea.2014.03.039

[4] Cardoso, R. P., Mafra, M., Brunatto, S. F.: Plasma Science and Technology - Progress in the Physical 
States and Chemical Reactions. 1st Edition. Rijeka, InTech 2016. doi:10.5772/61989

[5] Dong, H., Qi, P. Y., Li, X. Y., Llewellyn, R. J.: Mater. Sci. Eng. A, 431, 2006, p. 137. doi:10.1016/j.msea.2006.05.122

[6] Scheuer, C. J., Cardoso, R. P., Pereira, R., Mafra, M., Brunatto, S. F.: Mater. Sci. Eng. A, 539, 2012, p. 369. doi:10.1016/j.surfcoat.2012.10.060

[7] Gavriljuk, V. G., Berns, H.: High Nitrogen Steels. Berlin, Springer-Verlag 1999.

[8] Toro, A., Misiolek, W., Tschiptschin, A. P.: Acta Mater., 51, 2003, p. 3363. doi:10.1016/S1359-6454(03)00107-1

[9] Spies, H.-J., Berg, H.-J., Vogt, F., Serchen, B.: Advanced Engineering Materials, 2, 2000, p. 38. doi:10.1002/(SICI) 1527-2648(200002)2:1/2<38::AIDADEM38>3.0.CO;2-Q

[10] Borges, P. C., Rocha, L. A.: Kovove Mater., 49, 2011, p. 107. doi:10.4149/km_2011_2_107
[11] Reis, R. F., Maliska, A. M., Borges, P. C.: Mater. Sci., 46, 2011, p. 846. doi:10.1007/s10853-010-4827-3

[12] Lo, K. H., Shek, C. H., Lai, J. K. L.: Mater. Sci. Eng. R, 65, 2009, p. 39. doi:10.1016/i.mser.2009.03.001

[13] Cajner, F., Kovacic, S., Rafael, H., Vugrincic, A., Simunovic, V., Grzeta, B.: Mat.-Wiss. u. Werkstofftech., 46, 2015, p. 69. doi:10.1002/mawe.201400386

[14] Fontana, M. G.: Corrosion Engineering. 3th Edition. New York, McGraw-Hill 1986.

[15] Zhu, X. M., Lei, M. K.: Surf. Coat. Technol., 131, 2000, p. 400. doi:10.1016/S0257-8972(00)00856-2

[16] Lopez, D., Falleiros, N. A., Tschiptschin, A. P.: Wear, 263, 2007, p. 347. doi:10.1016/i.wear.2007.01.053

[17] Lu, S., Yao, K., Chen, Y., Wang, M., Liu, X., Ge, X.: Electrochim. Acta, 165, 2015, p. 45. doi:10.1016/j.electacta.2015.02.038 